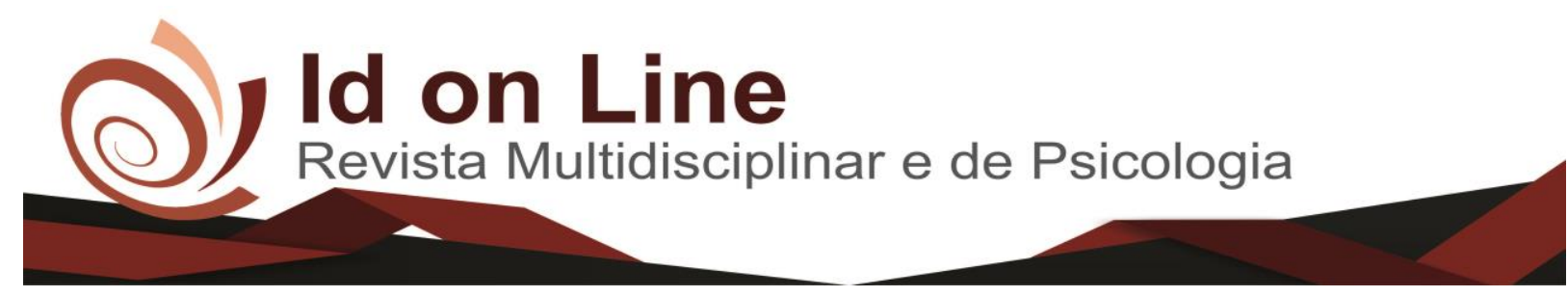

Artigo

\title{
Estabilização Segmentar Vertebral no Tratamento de Lombalgia: Uma Revisão Integrativa
}

Tiago Paixão Nascimento Aguiar ${ }^{\text {; }}$; Virgílio Santana Júnior ${ }^{2}$

\begin{abstract}
Resumo: O objetivo deste estudo é revisar a literatura científica em relação à estabilização segmentar vertebral e seus efeitos na lombalgia. Foi realizada uma busca nas bases de dados LILACS, SciELO e PEDro, no período de outubro a novembro de 2017, a partir do que foram selecionados nove artigos, todos publicados entre 2007 e 2017 , os quais abordavam a temática da estabilização segmentar com finalidade terapêutica. Os achados acerca da técnica de estabilização segmentar proporcionaram incremento no tratamento da lombalgia, o que permite concluir que as técnicas demonstraram eficácia com significância na melhora da capacidade funcional, na redução da dor e na prevenção de lesões.
\end{abstract}

Palavras-Chave: estabilização segmentar, lombalgia, lesões.

\section{Vertebral Segmental Stabilization in Low Back Pain Treatment: An Integrating Review}

Abstract: This study aimed to review the scientific literature regarding vertebral segmental stabilization and its effects on lower back pain. A search was carried out in the LILACS, SciELO, PEDro databases from October to November 2017, from which nine articles were selected, all published between 2007 and 2017, which addressed the theme of segmental stabilization with therapeutic purpose. The findings about the segmental stabilization technique provided an improvement in the treatment for lower back pain, which allows concluding that the techniques demonstrated efficacy with significance in the improvement of the functional capacity, the reduction of pain and the prevention of injuries.

Keywords: segmental stabilization, lower back pain, injuries.

\section{Introdução}

A dor lombar, ou lombalgia, é, na contemporaneidade, uma das principais causas de incapacidades, tornando-se um enorme obstáculo para a saúde pública e na qualidade de vida da sociedade moderna. A dor lombar aguda afeta cerca de $90 \%$ da população, sendo que os sinais e sintomas podem se apesentar diária ou semanalmente (BOTTAMEDI; SANTOS, 2016).

\footnotetext{
${ }^{1}$ Graduação em Fisioterapia pela Faculdade Independente do Nordeste.

${ }^{2}$ Fisioterapeuta. Especialista em Terapia Manual e Postural pelo CESUMAR (Centro Universitário de Maringá).
} 
A lombalgia é mundialmente representada com uma dor moderada ou intensa, que acomete em torno de 70 a $85 \%$ de adultos, tendo uma prevalência anual em 15 a $45 \%$ da população em fase produtiva (BOTTAMEDI; SANTOS, 2016).

A lombalgia crônica transcorre através da redução da instabilidade lombar, devido ao desequilíbrio de mecanismos como músculos, tendões, ligamentos, discos vertebrais, vértebras e do controle motor. As dores lombares podem ser causadas por fatores específicos (hérnias de discos, fraturas e osteoporose) e inespecíficos, que têm uma forte conexão com excesso de peso associado a posturas viciosas e inadequadas no dia a dia. Podem alterar a biomecânica da coluna lombar, causando dor e incapacidade no paciente (VOLPATO; WEBER, 2012).

Atualmente, devido ao alto índice de casos de lombalgia na população, certos recursos terapêuticos vêm sendo exibidos como opção para dor lombar ou lombalgia crônica. Várias formas de tratamento são propostas para prevenir e reduzir a dor, e restaurar a funcionalidade dos indivíduos. Sendo assim, a Estabilização Segmentar Vertebral (ESV) é um dos métodos que estão ganhando espaço na prevenção e intervenção do tratamento das lombalgias (BOTTAMEDI; SANTOS, 2016).

A técnica ESV é conhecida no meio cientifico como "Core Stabilization". A estabilização central é estabelecida como treinamento do complexo lombo-pelve-quadril, tendo com finalidade potencializar a flexibilidade distal, por meio de uma estabilização proximal, levando a uma integração do controle neuromuscular. Este treinamento do core tem por característica estimular e fortalecer os principais músculos comprometidos na biomecânica lombar, principalmente os músculos profundos inferiores, como o transverso do abdome e os multífidos. A ESV qualifica os músculos para atividade frequentes como as práticas esportivas, proporcionando mais qualidade nos movimentos e redução de riscos de lesões (BRANDÃO; PEREIRA, 2014).

Para Carla (2011), o principal músculo responsável pela estabilização da coluna lombar foi o transverso abdominal, ao tornar-se o primeiro músculo a ser ativado durante os movimentos. Sendo assim, este músculo é considerado fundamental na estabilização segmentar (ES). A técnica de ESV central ou core possui níveis e estágios avançados de obstáculo, nos quais a realização correta da técnica é essencial para oferecer um alinhamento biomecânico mais eficiente. Por esta razão, seu objetivo é promover níveis eficazes de força funcional, gerando estabilização dinâmica, criando um cinturão muscular na cintura pélvica, promovendo a rigidez necessária à coluna lombar e prevenindo a instabilidade postural. Diante disto, o 
objetivo deste estudo é revisar a literatura científica em relação à estabilização segmentar vertebral e seus efeitos na lombalgia.

\section{Metodologia}

Este estudo está direcionado a uma revisão integrativa da literatura, de caráter descritivo e exploratório e sem metanálise. Segundo Sampaio (2007), a pesquisa integrativa ocupa-se da busca por fontes de dados na literatura em relação à temática. Este estudo torna disponível uma síntese das evidências, através da execução de métodos explícitos, e regulariza a busca a partir da avaliação minuciosa do apanhado de informações escolhidas. Foi realizada uma busca nas bases de dados LILACS, SciELO e PEDro, no período de outubro a novembro de 2017. Os descritores utilizados foram "estabilização segmentar vertebral”, "estabilização segmentar vertebral na lombalgia" e "estabilização segmentar no tratamento de lombalgia crônica". Estes descritores foram pesquisados separadamente.

Para a pesquisa foram selecionados 117 artigos para realização da amostra, 9 se enquadrou nos critérios de inclusão, foram artigos incluindo estabilização segmentar vertebral de acordo com a temática e artigos publicados entre 2007 e 2017 originais. Foram excluídos da coleta artigos científicos em língua estrangeira, trabalhos cujas versões completas não se encontravam disponíveis, artigos que abordavam cirurgias e estabilização e artigos que não abordassem a temática.

O presente estudo é de extrema importância para avaliar a eficácia da técnica de estabilização segmentar vertebral em pacientes com dores lombares. Para a realização da coleta e tabulação dos dados, foi elaborada uma tabela de resultados que conta com a identificação dos seguintes tópicos: título, autores, ano de publicação, orientação metodológica, objetivos, população estudada e resultados obtidos. 


\section{Resultados}

Tabela 1. Dados sobre estabilização segmentar vertebral, com características metodológicas, objetivo e resultados encontrados.

\begin{tabular}{|c|c|c|c|c|c|}
\hline Título & Autor/Ano & $\begin{array}{c}\text { Orientação } \\
\text { Metodológica }\end{array}$ & Objetivo & Participantes & $\begin{array}{l}\text { Principais } \\
\text { resultados }\end{array}$ \\
\hline $\begin{array}{l}\text { Programa de } \\
\text { tratamento para } \\
\text { dor lombar } \\
\text { crônica } \\
\text { baseado nos } \\
\text { princípios da } \\
\text { Estabilização } \\
\text { Segmentar e na } \\
\text { Escola de } \\
\text { Coluna. }\end{array}$ & $\begin{array}{l}\text { Bottamedi, et } \\
\text { al, } 2016 .\end{array}$ & $\begin{array}{l}\text { Estudo } \\
\text { experimental. }\end{array}$ & $\begin{array}{l}\text { Analisar os efeitos } \\
\text { de um programa de } \\
\text { tratamento para } \\
\text { DL crônica, } \\
\text { baseado nos } \\
\text { princípios da } \\
\text { Estabilização } \\
\text { Segmentar (ES) e } \\
\text { na Escola de } \\
\text { Coluna (EC). }\end{array}$ & $\begin{array}{l}\text { G1 (ES): } 14 \\
\text { participantes, idade } \\
\text { média de } 55 \pm 7,8 \\
\text { anos, participantes } \\
\text { do programa de } \\
\text { exercícios baseado } \\
\text { nos princípios da } \\
\text { ES. } \\
\text { G2 (ES+EC): } 11 \\
\text { participantes. } \\
\text { Critério de } \\
\text { inclusão: pacientes } \\
\text { com diagnóstico } \\
\text { médico de DL } \\
\text { crônica (mais de } 3 \\
\text { meses), ambos os } \\
\text { sexos, faixa etária } \\
\text { entre } 18 \text { e } 65 \text { anos. } \\
\text { Foram excluídos } \\
\text { pacientes com dor } \\
\text { lombar de etiologia } \\
\text { específica (tumor, } \\
\text { hérnia discal, } \\
\text { síndrome facetaria, } \\
\text { estenose de canal, } \\
\text { entre outras), mais } \\
\text { de } 3 \text { faltas nas } \\
\text { sessões do } \\
\text { programa de } \\
\text { tratamento. }\end{array}$ & $\begin{array}{l}\text { O método } \\
\text { utilizado foi } \\
\text { diferente, visto } \\
\text { que realizaram } \\
\text { uma única sessão } \\
\text { semanal durante } \\
3 \text { meses. } \\
\text { Obtiveram bons } \\
\text { resultados na } \\
\text { redução da dor e } \\
\text { na melhora da } \\
\text { capacidade } \\
\text { funcional dos } \\
\text { pacientes } \\
\text { envolvidos. }\end{array}$ \\
\hline
\end{tabular}




\begin{tabular}{|c|c|c|c|c|c|}
\hline $\begin{array}{l}\text { Treinamento } \\
\text { De } \\
\text { Estabilização } \\
\text { Central em } \\
\text { Atletas de } \\
\text { Triathlon: Um } \\
\text { Estudo Clínico }\end{array}$ & $\begin{array}{l}\text { Brandão, et } \\
\text { al, } 2016 \text {. }\end{array}$ & $\begin{array}{l}\text { Estudo clínico } \\
\text { não } \\
\text { randomizado }\end{array}$ & $\begin{array}{l}\text { Analisar a } \\
\text { eficiência do } \\
\text { treinamento do } \\
\text { core no aumento } \\
\text { da estabilidade } \\
\text { lombopélvica em } \\
\text { adolescentes } \\
\text { praticantes de } \\
\text { triathlon }\end{array}$ & $\begin{array}{l}\text { Atletas atendidos } \\
\text { pelo projeto "O } \\
\text { Consolador" que } \\
\text { apresentavam } \\
\text { restrição à prática } \\
\text { de atividade física. } \\
\text { Critérios de } \\
\text { inclusão: idade } \\
\text { superior a } 8 \text { anos, } \\
\text { ser praticante de } \\
\text { triathlon } \\
\text { cadastrado e } \\
\text { atendido no projeto } \\
\text { "O Consolador". } \\
\text { Foram excluídos } \\
\text { menores que não } \\
\text { estivessem em } \\
\text { treinamento ou que } \\
\text { possuíssem } \\
\text { qualquer lesão } \\
\text { musculoesquelétic } \\
\text { a no momento da } \\
\text { triagem. }\end{array}$ & $\begin{array}{l}\text { O treinamento do } \\
\text { core não } \\
\text { provocou as } \\
\text { adaptações } \\
\text { neuromusculares } \\
\text { reportadas pela } \\
\text { literatura (não } \\
\text { teve } \\
\text { significância), } \\
\text { provavelmente } \\
\text { em virtude da } \\
\text { metodologia se } \\
\text { basear em apenas } \\
\text { um dia por } \\
\text { semana para a } \\
\text { realização do } \\
\text { treinamento }\end{array}$ \\
\hline $\begin{array}{l}\text { Exercícios de } \\
\text { estabilização } \\
\text { segmentar } \\
\text { lombar na } \\
\text { lombalgia: } \\
\text { revisão } \\
\text { sistemática da } \\
\text { literatura. }\end{array}$ & $\begin{array}{l}\text { Puzzoni, et } \\
\text { al, } 2012 \text {. }\end{array}$ & $\begin{array}{l}\text { Busca nas } \\
\text { bases de dados } \\
\text { PUBMED, } \\
\text { MEDLINE e } \\
\text { LILACS, no } \\
\text { período de } \\
2000 \text { a } 2010 .\end{array}$ & $\begin{array}{l}\text { Revisar a literatura } \\
\text { dos últimos dez } \\
\text { anos, para analisar } \\
\text { a eficácia dos } \\
\text { exercícios de } \\
\text { estabilização } \\
\text { segmentar nos } \\
\text { indivíduos com } \\
\text { lombalgia. }\end{array}$ & $\begin{array}{l}\text { Amostra inicial de } \\
61 \text { artigos. } 30 \text { após } \\
\text { a leitura dos } \\
\text { resumos. } 19 \text { que } \\
\text { cumpriram os } \\
\text { critérios de } \\
\text { inclusão. Critérios } \\
\text { de inclusão: } \\
\text { estudos sobre os } \\
\text { efeitos dos } \\
\text { exercícios de } \\
\text { estabilização } \\
\text { segmentar na dor } \\
\text { lombar, que } \\
\text { citavam a } \\
\text { importância dos } \\
\text { músculos } \\
\text { profundos na } \\
\text { manutenção da } \\
\text { estabilidade da } \\
\text { coluna vertebral, } \\
\text { ou que } \\
\text { comparavam o } \\
\text { efeito da } \\
\text { estabilização } \\
\text { segmentar com } \\
\text { outras técnicas de } \\
\text { tratamento para } \\
\text { lombalgia. Foram } \\
\text { excluídos estudos } \\
\text { com baixo grau de } \\
\text { evidência científica }\end{array}$ & $\begin{array}{l}\text { Comparando a } \\
\text { estabilização } \\
\text { com técnicas de } \\
\text { terapia manual, } \\
\text { um ensaio clínico } \\
\text { randomizado e } \\
\text { controlado (15) } \\
\text { concluiu que, } \\
\text { para indivíduos } \\
\text { com dor lombar } \\
\text { crônica, os } \\
\text { exercícios de } \\
\text { estabilização } \\
\text { segmentar foram } \\
\text { significativament } \\
\text { e mais eficazes } \\
\text { do que a terapia } \\
\text { manual em } \\
\text { relação à redução } \\
\text { da dor, } \\
\text { incapacidade, } \\
\text { consumo de } \\
\text { medicamentos e } \\
\text { qualidade de } \\
\text { vida. }\end{array}$ \\
\hline
\end{tabular}




\begin{tabular}{|c|c|c|c|c|c|}
\hline & & & & $\begin{array}{l}\text { e/ou publicados } \\
\text { antes de } 2000 .\end{array}$ & \\
\hline $\begin{array}{l}\text { Avaliação da } \\
\text { eficiência da } \\
\text { estabilização } \\
\text { central no } \\
\text { controle } \\
\text { postural de } \\
\text { atletas de base } \\
\text { de basquetebol. }\end{array}$ & $\begin{array}{l}\text { Carla, et al, } \\
2011\end{array}$ & $\begin{array}{l}\text { Estudo } \\
\text { analítico de } \\
\text { coorte, } \\
\text { intervencionist } \\
\text { a. }\end{array}$ & $\begin{array}{l}\text { Analisar a } \\
\text { eficiência da } \\
\text { estabilização } \\
\text { central no controle } \\
\text { postural dinâmico } \\
\text { em atletas de base } \\
\text { da Federação de } \\
\text { Basketball de } \\
\text { Alagoas (FBA), } \\
\text { para incrementar o } \\
\text { controle } \\
\text { neuromuscular, a } \\
\text { força, a potência e } \\
\text { a resistência } \\
\text { muscular, e } \\
\text { facilitar o } \\
\text { funcionamento } \\
\text { muscular } \\
\text { equilibrado de toda } \\
\text { cadeia cinética, } \\
\text { possibilitando a } \\
\text { eficiência motora } \\
\text { ideal ao longo do } \\
\text { sistema motor. }\end{array}$ & $\begin{array}{l}\text { A amostra de } 24 \\
\text { atletas da seleção } \\
\text { feminina de base } \\
\text { da FBA, com idade } \\
\text { entre } 16 \text { a } 18 \text { anos. } \\
\text { Critérios de } \\
\text { inclusão: atletas de } \\
\text { base, cadastrados e } \\
\text { em treinamento na } \\
\text { FBA. Foram } \\
\text { excluídos os atletas } \\
\text { portadores de } \\
\text { doença cardíaca } \\
\text { congênita, doença } \\
\text { respiratória não } \\
\text { tratada, desvios } \\
\text { vertebrais e } \\
\text { posturais } \\
\text { moderados ou } \\
\text { graves; atletas que } \\
\text { não estejam em } \\
\text { treinamento na } \\
\text { federação; idade } \\
\text { inferior a } 16 \text { anos e } \\
\text { superior a } 18 \text { anos. }\end{array}$ & $\begin{array}{l}\text { Para o teste do } \\
\text { Core, obteve-se } \\
\text { resultados } \\
\text { significativos } \\
\text { após intervenção } \\
\text { do Grupo } \\
\text { Estabilização: foi } \\
\text { encontrada } \\
\text { diferença de } \\
\text { média de 5,5 } \\
\text { mmHg quando } \\
\text { comparado ao } \\
\text { Grupo Controle, } \\
\text { obtendo p } \leq \\
\text { 0,001. É de } \\
\text { grande } \\
\text { importância o } \\
\text { trabalho de } \\
\text { estabilização } \\
\text { central em atletas } \\
\text { de basquetebol, } \\
\text { tendo uma } \\
\text { grande } \\
\text { movimentação e } \\
\text { coordenação, } \\
\text { visto que ao se } \\
\text { obter um core } \\
\text { forte e estável } \\
\text { pode-se } \\
\text { contribuir para } \\
\text { melhoria da } \\
\text { eficiência } \\
\text { neuromuscular, } \\
\text { auxiliando no } \\
\text { incremento da } \\
\text { dinâmica } \\
\text { desportiva e } \\
\text { prevenindo o } \\
\text { surgimento de } \\
\text { lesões. }\end{array}$ \\
\hline $\begin{array}{l}\text { Efetividade de } \\
\text { exercícios de } \\
\text { estabilização } \\
\text { segmentar } \\
\text { sobre a dor } \\
\text { lombar crônica } \\
\text { mecânico- } \\
\text { postural. }\end{array}$ & $\begin{array}{l}\text { Toledo, et al, } \\
2010 \text {. }\end{array}$ & $\begin{array}{l}\text { Análise } \\
\text { estatística } \\
\text { realizada de } \\
\text { forma } \\
\text { descritiva e } \\
\text { inferencial. }\end{array}$ & $\begin{array}{l}\text { Avaliar a } \\
\text { efetividade de } \\
\text { exercícios de } \\
\text { estabilização } \\
\text { segmentar sobre a } \\
\text { dor e a capacidade } \\
\text { funcional em } \\
\text { indivíduos com } \\
\text { lombalgia crônica. }\end{array}$ & $\begin{array}{l}\text { Amostra de } 12 \\
\text { jovens (18-32 } \\
\text { anos) com idade } \\
\text { média de } 20,66 \pm \\
3,74 \text { anos, que } \\
\text { apresentaram dor } \\
\text { lombar crônica } \\
\text { inespecífica. } \\
\text { Foram excluídos } \\
\text { sujeitos com } \\
\text { diagnóstico bem } \\
\text { definido de dor } \\
\text { ciática, frouxidão } \\
\text { da articulação } \\
\text { sacroilíaca, } \\
\text { espondilólise, } \\
\text { doença } \\
\text { neurodegenerativa, }\end{array}$ & $\begin{array}{l}\text { Após seis } \\
\text { semanas de } \\
\text { exercícios de } \\
\text { estabilização } \\
\text { segmentar, que } \\
\text { consistem na } \\
\text { contração da } \\
\text { musculatura } \\
\text { profunda do } \\
\text { tronco, } \\
\text { transverso do } \\
\text { abdômen e } \\
\text { multífido, houve } \\
\text { melhora da dor e } \\
\text { capacidade } \\
\text { funcional dos } \\
\text { indivíduos, } \\
\text { demonstrando }\end{array}$ \\
\hline
\end{tabular}




\begin{tabular}{|c|c|c|c|c|c|}
\hline & & & & $\begin{array}{l}\text { infecciosa ou } \\
\text { infamatória. }\end{array}$ & $\begin{array}{l}\text { ser um método } \\
\text { eficaz no } \\
\text { tratamento de } \\
\text { lombalgias. }\end{array}$ \\
\hline $\begin{array}{l}\text { Avaliação da } \\
\text { técnica de } \\
\text { estabilização } \\
\text { segmentar no } \\
\text { tratamento da } \\
\text { dor lombar } \\
\text { crônica. }\end{array}$ & $\begin{array}{l}\text { Alves, et al, } \\
2011 .\end{array}$ & $\begin{array}{l}\text { Estudo } \\
\text { transversal } \\
\text { experimental. }\end{array}$ & $\begin{array}{l}\text { Avaliar a técnica } \\
\text { de estabilização } \\
\text { segmentar lombar } \\
\text { (ESL) no } \\
\text { tratamento, em } \\
\text { curto prazo, das } \\
\text { dores lombares } \\
\text { crônicas. }\end{array}$ & $\begin{array}{l}23 \text { sujeitos de } \\
\text { ambos os sexos (14 } \\
\text { homens e } 9 \\
\text { mulheres; } \\
45,3 \pm 13,4 \text { anos; } \\
\text { massa corporal = } \\
73,9 \pm 13,2 \mathrm{~kg} ; \\
\text { estatura = } 169 \pm 0,1 \\
\text { m e índice de } \\
\text { massa } \\
\text { corporal/IMC = } \\
25,9 \pm 3,7 \mathrm{~kg} / \mathrm{m} 2), \\
\text { encaminhados ao } \\
\text { serviço de fi } \\
\text { sioterapia com } \\
\text { diagnóstico de } \\
\text { DLC (> } 3 \text { meses). } \\
\text { Todos passaram } \\
\text { por avaliação } \\
\text { analítica da } \\
\text { postura, em } \\
\text { bipedestação, e } \\
\text { quantificação da } \\
\text { dor (Escala Visual } \\
\text { Analógica }- \text { EVA), } \\
\text { pelo mesmo fi } \\
\text { sioterapeuta. } \\
\text { Foram excluídos } \\
\text { os sujeitos que não } \\
\text { completaram até a } \\
8^{\text {a }} \text { sessão de } \\
\text { tratamento, que } \\
\text { fizeram uso de } \\
\text { outro método } \\
\text { terapêutico, ou que } \\
\text { foram submetidos } \\
\text { a procedimentos } \\
\text { cirúrgicos na } \\
\text { coluna durante a } \\
\text { fase de tratamento. }\end{array}$ & $\begin{array}{l}\text { Houve diferença } \\
\text { estatisticamente } \\
\text { significante } \\
\text { quando } \\
\text { comparados os } \\
\text { níveis de dor na } \\
\text { Escala Visual } \\
\text { Analógica } \\
\text { (EVA), entre a } 1^{\text {a }} \\
\text { e a } 8^{\text {a }} \text { sessão de } \\
\text { tratamento de } \\
\text { estabilização } \\
\text { segmentar } \\
\text { (p=0,001). Dos } \\
23 \text { sujeitos da } \\
\text { amostra, } 3 \\
\text { permaneceram } \\
\text { no mesmo nível } \\
\text { de dor e } 20 \\
\text { relataram } \\
\text { redução } \\
\text { considerável do } \\
\text { nível doloroso. }\end{array}$ \\
\hline $\begin{array}{l}\text { A influência da } \\
\text { estabilização } \\
\text { segmentar } \\
\text { vertebral no } \\
\text { tratamento da } \\
\text { lombalgia por } \\
\text { disfunção } \\
\text { postural em } \\
\text { flexão }\end{array}$ & $\begin{array}{l}\text { Souza et al, } \\
2012\end{array}$ & $\begin{array}{l}\text { Revisão da } \\
\text { literatura com } \\
\text { quatro livros } \\
\text { das áreas de } \\
\text { cinesioterapia, } \\
\text { sendo dois } \\
\text { nacionais e } \\
\text { dois } \\
\text { importados, } \\
\text { dos períodos de } \\
2004 \text { a 2008. } \\
\end{array}$ & $\begin{array}{l}\text { Verificar a eficácia } \\
\text { da estabilização } \\
\text { segmentar } \\
\text { vertebral no } \\
\text { tratamento da } \\
\text { lombalgia por } \\
\text { disfunção postural } \\
\text { em flexão. }\end{array}$ & $\begin{array}{l}\text { Artigos coletados } \\
\text { nas bases de dados } \\
\text { Index Medicus, } \\
\text { Biological } \\
\text { Abstracts, Pub } \\
\text { Med, Bireme, } \\
\text { PEDro e Lilacs, } \\
\text { utilizando-se as } \\
\text { seguintes palavras- } \\
\text { chave: terapia } \\
\text { manual; exercícios }\end{array}$ & $\begin{array}{l}\text { Estudos } \\
\text { demonstraram } \\
\text { significativa } \\
\text { redução na } \\
\text { lombalgia pós- } \\
\text { parto de } \\
\text { mulheres tratadas } \\
\text { com exercícios } \\
\text { de estabilização } \\
\text { pélvica, quando } \\
\text { comparada a }\end{array}$ \\
\hline
\end{tabular}




\begin{tabular}{|c|c|c|c|c|c|}
\hline & & & & $\begin{array}{l}\text { de estabilização e } \\
\text { reabilitação e suas } \\
\text { similares em } \\
\text { Inglês. }\end{array}$ & $\begin{array}{l}\text { outros métodos } \\
\text { de tratamento } \\
\text { como } \\
\text { aconselhamentos } \\
\text { ergonômicos, } \\
\text { massagem, } \\
\text { mobilização e } \\
\text { manipular } \\
\text { articular, } \\
\text { eletroterapia e } \\
\text { compressas } \\
\text { quentes na } \\
\text { região. }\end{array}$ \\
\hline $\begin{array}{l}\text { A eficácia da } \\
\text { estabilização } \\
\text { segmentar } \\
\text { vertebral no } \\
\text { aumento do } \\
\text { trofismo dos } \\
\text { multífidos e } \\
\text { melhora da dor } \\
\text { em portadores } \\
\text { de hérnia discal } \\
\text { lombar. }\end{array}$ & $\begin{array}{l}\text { Rocha, et al, } \\
2014\end{array}$ & $\begin{array}{l}\text { Estudo do tipo } \\
\text { série de casos, } \\
\text { intervencional. }\end{array}$ & $\begin{array}{l}\text { Avaliar a eficácia } \\
\text { da técnica de } \\
\text { Estabilização } \\
\text { Segmentar } \\
\text { Vertebral (ESV) } \\
\text { no aumento do } \\
\text { trofismo dos } \\
\text { multífidos e na } \\
\text { melhora da dor em } \\
\text { pacientes } \\
\text { portadores de } \\
\text { Hérnia Discal } \\
\text { Lombar (HDL). }\end{array}$ & $\begin{array}{l}\text { Pacientes de } \\
\text { ambos os sexos, } \\
\text { com idade entre } 25 \\
\text { e } 50 \text { anos } \\
\text { ( } 41,17+7,47 \text { anos), } \\
\text { IMC entre } 18,5 \\
\mathrm{Kg} / \mathrm{m}^{2} \text { e } 30 \mathrm{Kg} / \mathrm{m}^{2} \\
(24,93+2,97), \\
\text { histórico álgico na } \\
\text { lombar de, no } \\
\text { mínimo, seis } \\
\text { meses, portadores } \\
\text { de Hérnia de Disco } \\
\text { Lombar em L4/L5 } \\
\text { ou L5/S1, } \\
\text { diagnosticada por } \\
\text { um médico, e } \\
\text { confirmada por } \\
\text { exame de } \\
\text { ressonância } \\
\text { magnética. } \\
\text { Critérios de } \\
\text { exclusão: } \\
\text { realização de } \\
\text { alguma cirurgia ou } \\
\text { sequela de fratura } \\
\text { na coluna } \\
\text { vertebral, } \\
\text { distúrbios } \\
\text { neurológicos, } \\
\text { portadores de } \\
\text { doenças reumáticas } \\
\text { crônicas e } \\
\text { gestantes. Dez } \\
\text { pacientes foram } \\
\text { recrutados através } \\
\text { das listas de espera } \\
\text { do Departamento } \\
\text { de Fisioterapia da } \\
\text { Universidade } \\
\text { Federal de } \\
\text { Pernambuco } \\
\text { (UFPE) e da } \\
\text { Faculdade Estácio } \\
\text { do Recife. }\end{array}$ & $\begin{array}{l}\text { Houve um } \\
\text { aumento do } \\
\text { trofismo dos } \\
\text { multífidos, tanto } \\
\text { ântero-posterior } \\
\text { quanto látero- } \\
\text { lateral, assim } \\
\text { como pode ser } \\
\text { observada a } \\
\text { contração efetiva } \\
\text { dos } \\
\text { estabilizadores } \\
\text { em todos os } \\
\text { pacientes após a } \\
\text { intervenção. } \\
\text { Apesar de não } \\
\text { promover o } \\
\text { alívio completo } \\
\text { do quadro álgico, } \\
\text { foi verificado } \\
\text { que esta técnica } \\
\text { promove uma } \\
\text { redução nível da } \\
\text { dor. }\end{array}$ \\
\hline
\end{tabular}

Fonte: Pesquisa do autor 


\section{Discussão}

Esta revisão integrativa demonstrou que há comprovação de evidências cientificas apontando que a técnica de estabilização segmentar vertebral é eficaz, uma vez que obteve evolução no tratamento da lombalgia, na melhora da capacidade funcional, na obtenção de um core forte, melhorando a eficácia neuromuscular, e, consequentemente, prevenindo lesões.

Alves et al. (2011) destaca que o exercício de estabilização segmentar promoveu eficácia no tratamento de dor lombar, tendo melhoras estimadas em cerca de $87 \%$ dos indivíduos, no período de quatro semanas de intervenção. Já Toledo et al. (2010), afirma que a aplicação da técnica de estabilização segmentar lombar obteve eficácia na redução da dor e da incapacidade em pessoas com lombalgia em um período de seis semana de execução da técnica.

Foram detectados sete artigos cientifico com grande semelhança, comprovando que a técnica de estabilização segmentar é um excelente recurso terapêutico para o tratamento de lombalgia, trazendo grande redução da dor, melhora na incapacidade funcional e prevenção de lesão (BRANDÃO, 2014; BOTTAMEDI et al., 2011; ROCHA et al., 2014; PUZZONI et al., 2012; SOUZA et al., 2010; ALVES et al., 2011; TOLEDO et al., 2010).

Carla et al. (2011), verificou o controle postural dinâmico em atletas de basquetebol. O resultado encontrado é o de que os atletas possuem déficit na redução mecânica, dor articular e muscular, baixo desempenho no esporte e alto índice de lesões, proporcionando uma sobrecarga no sistema musculoesquelético. Porém, com a intervenção da estabilização segmentar, tem-se obtido melhoras significativa na capacidade de controlar as mobilidades do tronco, melhorando a funcionalidade dos atletas, a força estática e a resistência, a eficácia no desempenho dinâmico, a melhora no equilíbrio de pélvico, a diminuição gasto energético em membros inferiores durante as práticas de atividade física, e, consequentemente, reduzindo a probabilidade de lesões, proporcionando melhor evolução motora dos atletas.

No estudo sobre indivíduos com dor lombar ou lombalgia de Flávia et. al. (2014), acerca dos exercícios de estabilização segmentar "Core", a técnica parte do comprometimento fisiológico de instabilidade, que é classificado como lesão tecidual gerada por desordem funcional devido uma redução de força, causando um desalinhamento na posição lombar. Por meio destas alterações de instabilidade, a técnica permite recuperar as funcionalidades das estruturas comprometidas.

Segundo Toledo et al. (2010), os indivíduos com dor lombar que foram submetidos à aplicação dos exercícios de estabilização segmentar em um período de seis semana de execução 
da técnica, com intervenção de mais de três vezes por semana obtiveram eficácia em seus resultados.

Em outra perspectiva, o estudo de Brandão et. al. (2014) evidencia que a aplicação da técnica de estabilização segmentar em indivíduos com lombalgia não teve significância quando realizada em uma pequena amostra, com pouca quantidade de sessões e intervenções menores que três vezes por semana. Sendo assim, é importante destacar que uma frequência maior de intervenções gera bons resultados no tratamento da dor lombar.

Portanto, os estudos apontam que a técnica de ESV tem resultados satisfatórios, demonstrando eficiência na sintomatologia, diminuição da dor e incapacidade, em casos de lombalgia aguda, crônica e prevenção.

\section{Conclusão}

Neste estudo, foi analisada cientificamente a técnica de ESV, a qual mostrou ser eficaz na prevenção e no tratamento de portadores de lombalgia, melhorando suas funcionalidades. Este exercício aparenta ter resultados excelentes, se comparado a outras técnicas de terapia manual.

A finalidade desta revisão é trazer embasamento para o meio cientifico sobre o referente assunto, referenciando os benefícios da técnica, proporcionando melhor capacidade funcional e promovendo uma melhor qualidade de vida aos indivíduos. Pretende-se, com este estudo, auxiliar profissionais e acadêmicos no sentido de que eles estejam qualificados a realizar um tratamento mais eficaz para seus pacientes, levando em consideração as suas individualidades.

\section{Referências}

BOTTAMEDI, X. et al. Programa de tratamento para dor lombar crônica baseado nos princípios da Estabilização Segmentar e na Escola de Coluna. Rev. Bras. Med. Trab., 2016; 14 (3): 206-13.

CARVALHO, A. C. A; LINS, M. C. T., et al. Avaliação da eficiência da estabilização central no controle postural de atletas de base de basquetebol. Curso de Fisioterapia da Faculdade de Ciências Biológicas e da Saúde - FCBS/CESMAC, Maceió, 2011.

KOBILL, M. F. A., et al. Influência da estabilização segmentar core na dor e funcionalidade da coluna lombar. Fisioterapia Brasil, 2017; 18 (2): 148-153. 
LACERDA, B. F; MACÊDO, P. M; CARVALHO, A. C. L. Treinamento de Estabilização Central em Atletas de Tiathlon: Um Estudo Clínico. Curso de Fisioterapia, Centro Universitário CESMAC. Rev. Fisioter S. Fun., Maceió, ago. / dez. 2014; 3 (2): 24-30.

MENDES, S. A. H; FRACARO, G., et al; Avaliação da técnica de estabilização segmentar no tratamento da dor lombar crônica. Ter Man. 2011; 9 (43): 178-184.

PEREIRA, T. N.; FERREIRA, B. F. L; PEREIRA, M. W. Efetividade de exercícios de estabilização segmentar sobre a dor lombar crônica mecânica-postural. Fisioter. Mov., Curitiba, v. 23, n. 4, p. 605614, out. / dez. 2010.

SAMPAIO R. F.; MANCINI, M. C. Estudos de revisão sistemática: um guia para síntese criteriosa da evidência científica. Departamento de Fisioterapia e de Terapia Ocupacional, Escola de Educação Física, Fisioterapia e Terapia Ocupacional, Universidade Federal de Minas Gerais, Belo Horizonte, MG - Brasil. Rev. Bras. Fisioter. São Carlos, v. 11, n.1, p. 83-89, jan. / fev. 2007.

SIQUEIRA, G. R; ALENCAR, G. G; OLIVEIRA, N. K; LEITE, F. N. T. S. A eficácia da estabilização segmentar vertebral no aumento do trofismo dos multífidos e melhora da dor em portadores de hérnia discal lombar. Rev. Bras. Ci. E Mov. 2014; 22 (1): 81-91.

SOUZA, N. S. et al. A influência da estabilização segmentar vertebral no tratamento da lombalgia por disfunção postural em flexão. Fisioterapia Ser. Vol. 5 - nº 3, 2010.

VOLPATO, P. C; FERNANDES, W. S. et al. Exercício de estabilização segmentar lombar na lombalgia: revisão sistemática da literatura. Arq. Med. Hosp. Fac. Cienc. Med. Santa Casa São Paulo, 2012.

\section{Como citar este artigo (Formato ABNT):}

VAEGES, Luana M. de S.; BARBOSA, Mirella C. L. Fatores Relacionados ao Afastamento de Enfermeiros em um Hospital Público do Município de Vitória da Conquista. Id on Line Revista Multidisciplinar e de Psicologia, 2017, vol.11, n.38, p.678-688. ISSN: 1981-1179.

Recebido: 07.11.2017

Aceito: 09.11.2017 